\title{
Synchronous Cultures of Micro-organisms: Large-scale Preparation by Continuous-flow Size Selection
}

\author{
BY D. LLOYD, LYNDA JOHN, C. EDWARDS* \\ AND A. H. CHAGLA \\ Department of Microbiology, University College, \\ Cardiff $\mathrm{CF}_{2}$ I $T A$
}

(Received 22 November 1974; revised 28 December 1974)

\begin{abstract}
SUMMAR Y
The separation of the smallest cells from an exponentially growing culture by passage through a continuous flow centrifuge rotor under controlled conditions of rotor speed and flow rate, provides a simple method for the rapid production of large-scale synchronous cultures. The effluent from the rotor, containing the smallest-sized class of organisms, still suspended in their growth medium and still growing undisturbed throughout this rapid procedure, provides a culture which goes on to exhibit synchronous cell division. Successfully applied to budding and fission yeasts and to amoeboid and ciliated protozoa, this procedure is potentially applicable to any non-filamentous, non-aggregating, unicellular organism or to cells of higher plants or animals growing in liquid tissue-cultures.
\end{abstract}

\section{INTRODUCTION}

Two broad classes of techniques are employed to prepare synchronous cultures: 'induction synchrony' in which all the cells of a culture are induced to divide synchronously by some physical or chemical treatment, and 'selection synchrony' in which cells at a particular stage of the cycle are separated and allowed to grow through their natural cycle (James, 1964). Selection synchrony is the method of choice when events occurring during the normal cell cycle are to be studied, as induction synchrony involves metabolic stress or interference.

One simple widely used method for selection of the smallest cells of a culture is based on differential sedimentation of the exponentially growing cell population through a sucrose density gradient (Mitchison \& Vincent, 1965). A major drawback of this method is the low yield. Scale-up has been achieved using the greater gradient capacity offered by zonal rotors (Poole, Lloyd \& Kemp, 1973; Poole \& Lloyd, 1973). However, the time required for separation may be up to $\mathrm{I} h$, during which the organisms are exposed to a sub-optimal temperature and anaerobic conditions. The method is not applicable to osmotically fragile organisms (e.g. many protozoa); even elimination of high osmotic pressures by the substitution of high-molecular-weight gradient media does not prevent distortion of the first subsequent cell-cycle (Edwards, Statham \& Lloyd, I975). Velocitysedimentation size selection cannot be applied to organisms showing rapid motility and is almost impossible to conduct aseptically. Similar criticisms apply to the alternative approach of cell-cycle fractionation, although in this case the yield of cells is high when large-volume zonal rotors are employed (Warmsley \& Pasternak, 1970; Sebastian, Carter \& Halvorson, 197I; Poole \& Lloyd, 1973; Poole, Lloyd \& Chance, I974).

* Present address: Department of Biochemistry, The University, Leicester LEI 7 RH. 
The method described here obviates all these difficulties, and fails only exceptionally (e.g. with aggregating or flocculating cultures, or where the smallest-sized class of organisms is non-viable). It has been successfully applied to the preparation of synchronous cultures over the past two years. During the course of the work, Knutsen et al. (1973) applied a similar technique to Chlamydomonas reinhardti.

\section{METHODS}

Organisms. Methods for the maintenance and growth of organisms have been described for Schizosaccharomyces pombe 972h- (Poole et al. 1973), Candida utilis NCYC193 (Light \& Garland, 197I), Tetrahymena pyriformis strain ST (Lloyd et al. 197I), Acanthamoeba castellanii (Griffiths \& Chagla, 1972), and Crithidia fasciculata (Edwards \& Lloyd, 1973). The major carbon source in the yeast cultures was glucose.

Cell numbers. Cells were counted in a Thoma haemocytometer slide (Hawksley, Lancing, Sussex) or, for $T$. pyriformis in a Sedgewick-Rafter cell (Graticules Ltd, Tonbridge, Kent).

Centrifugation. The culture (mid- to late-exponential phase of growth) was siphoned from the growth vessel through a 'continuous action rotor' fitted with a high-efficiency polypropylene insert running in a High Speed 8 centrifuge (MSE Ltd, Crawley, Sussex) (Fig. I). This rotor achieves rate-separation of suspended particles during flow through the main compartment and through the vertical holes in the insert. The maximum flow rate is $21 / \mathrm{min}$, and maximum rotor speed $18000 \mathrm{rev} . / \mathrm{min}$; suspended particles may be collected until a packed cell volume of $300 \mathrm{ml}$ has accumulated in the rotor. Suitable flow rates (in the range 300 to $2000 \mathrm{ml} / \mathrm{min}$ ) were provided by inclusion of one of a series of calibrated tapered glass tubes in the inlet gravity feed. Accurate control of rotor speed at less than $1800 \mathrm{rev} . / \mathrm{min}$ was by means of a 'low-speed zonal control' ancillary circuit fitted to the centrifuge. Preliminary experiments established optimum conditions for the retention of about $90 \%$ of the cells of a growing culture; those for a range of eukaryotic micro-organisms are given in the legend to Fig. 3. Rotor effluent (containing the smallest cells of the culture) was aerated at the temperature of growth and provided the starting material for synchronous growth. The whole procedure could be carried out aseptically by autoclaving the rotor after plugging its ports with cotton wool and using a liquid seal in the rotor lid (Fig. I).

Assessment of synchrony. The degree of synchrony was assessed by the synchrony index, $F$, of Blumenthal \& Zahler (I962), calculated from the equation:

$$
F=\left(N / N_{0}\right)-2^{t / g},
$$

where $F$ has a maximum value of I 0 in a culture exhibiting theoretically perfect synchrony, $N$ is the number of organisms at time $t, N_{0}$ the number of organisms at zero time, and $g$ the mean generation time.

In the presentation of results, vertical lines indicate the mid-points of doublings in cell numbers, and $F_{1}$ and $F_{2}$ denote the synchrony indices of the first and second doublings in cell numbers, respectively.

\section{RESULTS}

Frequency histograms of cell volumes of $S$. pombe, from an exponentially growing culture and from the rotor effluent, are shown in Fig. 2. Growth curves for this fission yeast, the budding yeast Candida utilis, the ciliated protozoon $T$. pyriformis, the amoeba 

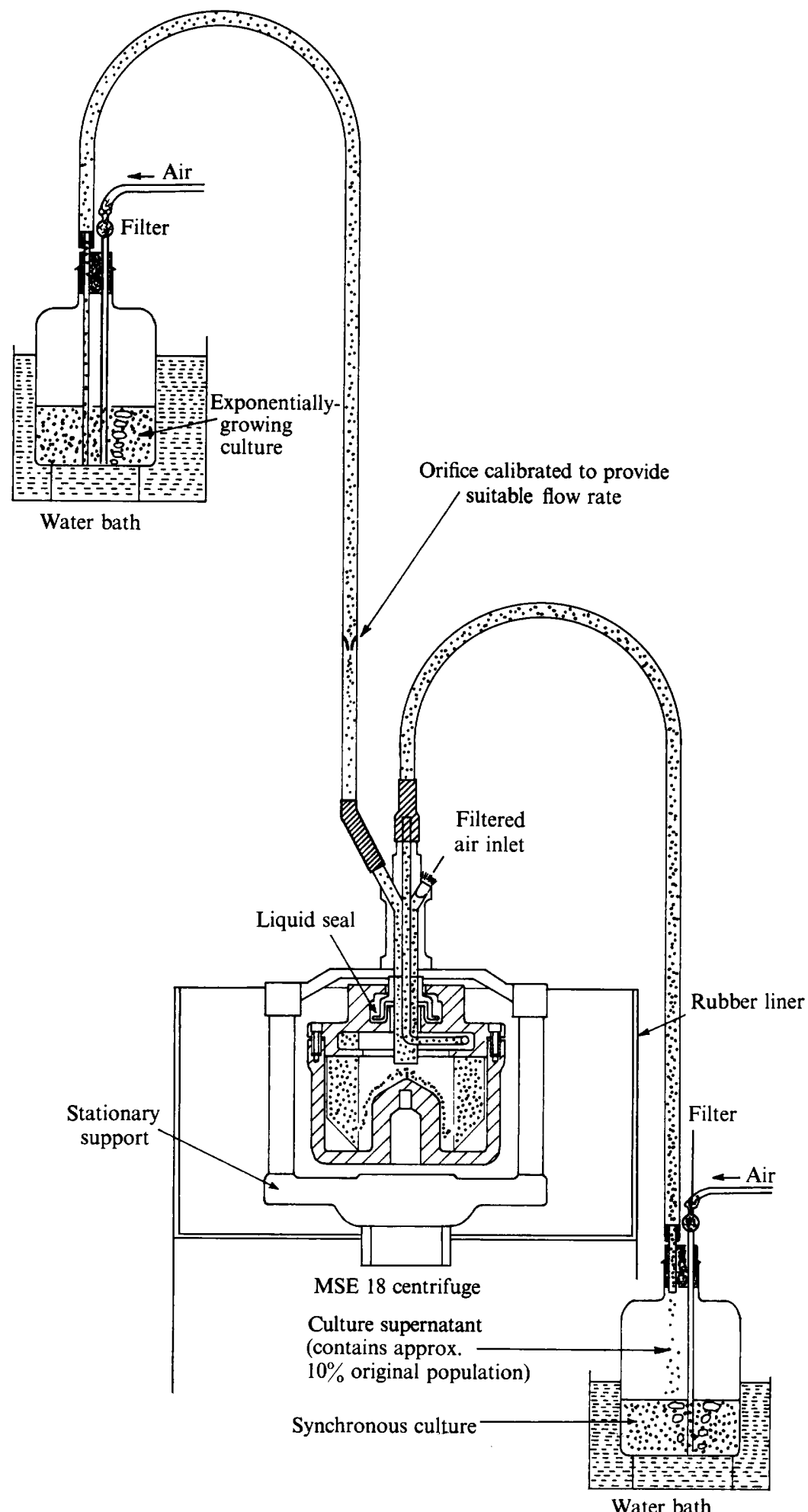

Fig. I. Diagram of apparatus for the preparation of synchronous cultures by continuous flow size selection using the MSE 'continuous action rotor' (for details see text). 

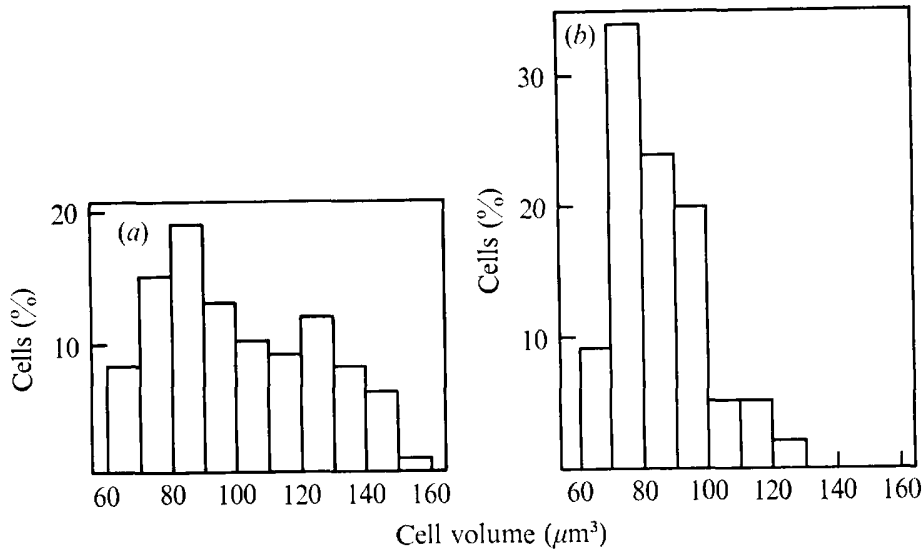

Fig. 2. Size distribution of cell populations of $S$. pombe in $(a)$ an exponentially growing culture and $(b)$ a sample of the effluent from the continuous flow rotor which contained $10.5 \%$ of the initial population; rotor speed $3000 \mathrm{rev} . / \mathrm{min}$, flow rate $620 \mathrm{ml} / \mathrm{min}$. Cell volumes were calculated for at least 100 randomly selected cells from measurements with an image-splitting eyepiece (Poole, Lloyd \& Kemp, 1973).


Fig. 3. Cell numbers in synchronous cultures prepared by continuous flow size selection. Organisms were grown in batch cultures to the mid-exponential phase of growth. The cultures were passed through the continuous flow rotor (conditions in parentheses), and cell numbers were followed during culture of the rotor effluent. $F_{1}$ and $F_{2}$ indicate synchrony indices in the first and second divisions respectively. (a) Schizosaccharomyces pombe $972 \mathrm{~h}^{-}(3000 \mathrm{rev} . / \mathrm{min}, 600 \mathrm{ml} / \mathrm{min}, 10 \%$ of original population in rotor effluent). (b) Candida utilis NCYCI93 (4000 rev. $/ \mathrm{min}, 420 \mathrm{ml} / \mathrm{min}$, I $3 \%$ of original population in rotor effluent). (c) Tetrahymena pyriformis ST (700 rev. $/ \mathrm{min}, 420 \mathrm{ml} /$ min, $10 \%$ of original population in rotor effluent). (d) Acanthamoeba castellanii ( $1000 \mathrm{rev} . / \mathrm{min}$, $380 \mathrm{ml} / \mathrm{min}$, I I \% of original population in rotor effluent). (e) Crithidia fasciculata (3800 rev./min, $100 \mathrm{ml} / \mathrm{min}$, I $\%$ of original population in rotor effluent). 
A. castellanii, and the trypanosomatid Crithidia fasciculata are shown in Fig. 3. For each of the first four organisms satisfactory synchrony of cell division was achieved, in that cell counts indicated an accurate doubling in numbers over a time interval which was short compared with the mean generation time. The duration of the cell cycle was very similar to the mean generation time of exponentially growing cultures. For $C$. fasciculata the degree of synchrony was not good; only $45 \%$ of the organisms underwent division, because many of the smallest cells were not viable.

\section{DISCUSSION}

The method described has many advantages. Growth of the culture is not interrupted by changes of temperature or by a fall in oxygen tension, as it was only in the rotor for a few seconds. Nutrient status is preserved, as the organisms are not removed from the medium. Synchronous cultures may be established within a few minutes. The method may be applied to large volumes; for large cultures, rapid flow rates (up to $21 / \mathrm{min}$ ) are necessary to reduce the total time of collection to a minimum, especially for organisms with short cell-cycle times: we have successfully applied the procedure to cultures of 201. The only limitation in terms of cell density is that sufficient limiting nutrient must remain to support $10 \%$ of the population through one further cycle, i.e. selection must be carried out before the original culture attains a population one generation before the stationary phase of growth. The procedure may be carried out under strictly aseptic conditions. This is necessary for slow-growing organisms in complex growth media (e.g. for $A$. castellannii and $C$. fasciculata) and we have occasionally followed growth for as long as $24 \mathrm{~h}$ without noting any contamination. Williams (I972) has reported a lower limit of $60 \mathrm{~N} \mathrm{~m}^{-2}$ for the shear stress required to disrupt amoebae exposed to mechanical stress for periods of the order of I ms. The usefulness of the procedure with such an easily disrupted organism as $A$. castellanii suggests that the liquid shearing forces generated are not sufficient to damage even the most fragile cell-types. Other continuous flow centrifuges, e.g. those manufactured by International Equipment Co., Needham Heights 94, Massachusetts, U.S.A. (Helixtractor), Alpha Laval Co. Ltd, Brentford, Middlesex (LAB 102 B-25), or Sharples International, Pennsalt, Camberley, Surrey could be used provided they are fitted with a variable speed-control rheostat. The greater path length of a continuous flow zonal rotor (e.g. the CF-6 rotor of a PR-60oo centrifuge, Damon, Needham Heights) would not improve the synchrony indices obtained, and would be $\mathrm{i}_{\text {mpossible to }}$ use aseptically. The maximum useful size resolution is limited by the extent to which cells at the same stage of the cycle vary in size.

The method is potentially applicable to cultures of any non-filamentous, non-aggregating organism, irrespective of size, shape or motility, provided that the smallest cells of the culture are all viable.

Preliminary work with Dr J. L. Moore suggests that it can be applied to mammalian cells in tissue culture, and that the maximum rotor speed ( $18000 \mathrm{rev} . / \mathrm{min}$ ) is adequate for the size-selection of bacteria.

This work was carried out during the tenure of a Science Research Council postgraduate studentship (C.E.) and a Tenovus postgraduate award (A. H.C.). 


\section{REFERENCES}

Blumenthal, L. K. \& ZAHLER, S. A. (1962). Index for measurement of synchronization of cell populations. Science, New York 135, 724.

EDWARDS, C. \& Lloyd, D. (I973). Terminal oxidases and carbon monoxide-reacting haemoproteins in the trypanosomatid, Crithidia fasciculata. Journal of General Microbiology 79, 275-284.

Edwards, C., Statham, M. \& Lloyd, D. (1975). The preparation of large-scale synchronous cultures of the trypanosomatid, Crithidia fasciculata, by cell-size selection: changes in respiration and adenylate charge through the cell-cycle. Journal of General Microbiology 88, I41-1 52.

Griffiths, A. J. \& Chagla, A. H. (1972). The growth and encystment of Hartmanella castellanii. Journal of Protozoology S r9, A I 30.

James, T. W. (1964). In Synchrony in Cell Division and Growth, pp. 323-349. Edited by E. Zeuthen. New York: Interscience.

Knutsen, G., Lien, T., Schreiner, Ø. \& VAaGe, R. (1973). Selection synchrony of Chlamydomonas using the Rastgeldi threshold centrifuge. Experimental Cell Research 8r, 26-28.

Light, P. A. \& Garland, P. B. (197I). A comparison of mitochondria from Torulopsis utilis grown in continuous culture with glycerol, iron, ammonium, magnesium or phosphate as the growth-limiting nutrient. Biochemical Journal 124, $123-134$.

Lloyd, D., Brightwell, R., Venables, S. E., Roach, G. I. \& Turner, G. (1971). Subcellular fractionation of Tetrahymena pyriformis ST by zonal centrifugation: changes in activities and distribution of enzymes during the growth cycle and on starvation. Journal of General Microbiology 65, 209-223.

Mitchison, J. M. \& Vincent, W. S. (I965). Preparation of synchronous cultures by sedimentation. Nature, London 205, 987-989.

Poole, R. K. \& LloYD, D. (1973). Oscillations of enzyme activities during the cell-cycle of a glucoserepressed fission yeast, Schizosaccharomyces pombe. Biochemical Journal 136, 195-207.

Poole, R. K., Lloyd, D. \& Chance, B. (1974). The development of cytochromes during the cell cycle of a glucose-repressed fission yeast, Schizosaccharomyces pombe. Biochemical Journal 138, $201-210$.

Poole, R. K., LloyD, D. \& KeMP, R. B. (I973). Respiratory oscillations and heat evolution in synchronously dividing cultures of the fission yeast, Schizosaccharomyces pombe. Journal of General Microbiology 77, 209-220.

Sebastian, J., Carter, B. L. A. \& Halvorson, H. O. (I97I). Use of yeast populations fractionated by zonal centrifugation to study the cell cycle. Journal of Bacteriology ro8, 1045-1050.

Warmsley, A. M. H. \& Pasternak, C. A. (1970). The use of conventional and zonal centrifugation to study the life cycle of mammalian cells. Biochemical Journal II9, 493-499.

Williams, R. (1972). Disorganization and disruption of mammalian and amoeboid cells by acoustic microstreaming. Journal of the Acoustical Society of America 52, 688-693. 